\title{
International Environment Financing: A Review of the Global Environment Facility
}

\author{
Empire Hechime Nyekwere*
}

DOI: $10.21827 / 5 \mathrm{a} 6 \mathrm{afa} 321 \mathrm{fa} 06$

\section{Keywords}

INTERNATIONAL ENVIRONMENTAL FINANCING; INTERNATIONAL
ENVIRONMENTAL CONVENTIONS; GLOBAL ENVIRONMENT FACILITY

\begin{abstract}
After having played the part of a path-breaker and trend-setter in the early years of its existence, the Global Environment Facility (GEF) came to occupy a vital and wellestablished place in international environmental governance (IEG) from the end of the 1990's onwards. At present, the GEF faces some obvious challenges that threaten to weaken its stature in the global environmental architecture, namely the issues of its efficiency and role in its current form. The proliferation of new funds and funding machineries over the past years is bringing about major changes in the roles of different funding institutions, including the GEF. Particularly, they result in shifting funds for the GEF's focal areas from the GEF to other funding institutions, such as the World Bank and other Multilateral Development Banks (MDBs), which in the opinion of many scholars may relegate the GEF to a minor role in the existing organizational architecture for global environmental financing. As an international funding mechanism approving hundreds of millions of dollars in grants each year, the GEF presents tremendous potential to address some of the most pressing environmental problems threatening human prosperity and survival. The paper, therefore, reviews the Global Environment Facility as an important player in the field of international environmental governance, particularly as it relates to its role within the existing organizational architecture for international environmental financing.
\end{abstract}

\section{Introduction}

The Global Environment Facility (GEF) is an independent and international financial organization established in October 1991 to assist in the protection of the global environment and the promotion of environmentally sound and sustainable economic development ${ }^{1}$ through financial support to environmental and climate elements in development projects in low-and middle-income countries. ${ }^{2}$ The GEF serves as a consolidated financial mechanism for funding global environmental issues and associated

\footnotetext{
Lecturer, Institute of Continuing Education, Law Diploma Programme, Port Harcourt Polytechnic, Rivers State, Nigeria. International Environmental Law Ph.D. Student at Faculty of Law, Department of International Law and Jurisprudence, Nnamdi Azikiwe University, Awka, Anambra State, Nigeria. The author is a Nigerian national and Barrister \& Solicitor of the Supreme Court of the Federal Republic of Nigeria. E-mail: empire.hechime@yahoo.com

1 World Bank, Global Environment Facility, Operations Manual - Global Environment Facility Operations, at <policies.worldbank.org/sites/ppf3/PPFDocuments/090224b08231a89b.pdf> (accessed 19 November 2017).

2 Government Offices of Sweden, Organization Strategy for Sweden's Cooperation with the Global Environmental Facility (GEF) 2016-2018, at <government.se/country-and-regional-strategies/ 2016/11/organisation-strategy-for-swedens-cooperation-with-the-global-environmental-facility-gef20162018/> (accessed 18 November 2018).
} 
multilateral environmental agreements ${ }^{3}$ by transferring resources North to South to meet the commitments of the new Rio Environmental Conventions. ${ }^{4}$ The GEF emerged from the concern over global environmental issues expressed predominately by industrialized countries, such as France, Germany, etc. in the late 1980s. ${ }^{5}$ Further support for the GEF came from the United Nations Conference on Environment and Development (UNCED), held in 1992, and the Climate and Biodiversity Conventions with their provisions for financial mechanisms. Donor governments hoped to avoid a proliferation of new funding mechanisms for diverse environmental purposes and therefore stressed that one facility, ${ }^{6}$ administered by existing institutions, serves the various global environmental conventions. ${ }^{7}$

The Global Environment Facility (GEF) operates as the financial mechanism for the major international environmental conventions: the United Nations Framework Convention on Climate Change (UNFCCC) (1992), the Convention on Biological Diversity (CBD) (1992), the United Nations Convention to Combat Desertification (UNCCD) (2003), and the Stockholm Convention on Persistent Organic Pollutants (POPs) (2001). ${ }^{8}$ The Global Environment Facility also supports other multilateral initiatives. ${ }^{9}$ For example, the GEF establishes operational guidance for international waters and ozone activities, the latter consistent with the Montreal Protocol on Substances that Deplete the Ozone. The GEF unites 182 member governments and partners with international institutions, non-governmental organisations and the private sector to assist developing countries and economies-in-transition, ${ }^{10}$ fund environmental projects and shape policy reform in six focal areas - biodiversity, climate change,

3 Nakhooda, S, and Forstater, M, The Effectiveness of Climate Finance: A Review of the Global Environment Facility, October 2013, at <odi.org/sites/odi.org.uk/files/odi-assets/publications-opinionfiles/863.pdf $>$ (accessed on 18 November 2017); European Parliament Think Tank, Moosmann, L, et al., International Climate Negotiations - on the Road to Paris - Issues at Stake in View of COP 21, 16, at (accessed 22 November 2017).

4 The Global Environment Facility, Horta, K, Report: The First Ten Years - Growing Pains or Inherent Flaws, August 2002, at <halifaxinitiative.org/content/global-environment-facility-first-ten-yearsgrowing-pains-or-inherent-flaws-august-2002> (accessed on 18 November 2017).

5 Cohen, S, and Burgiel, SW, The Global Environment Facility from Rio to New Delhi: A Guide for NGO's, IUCN Gland, 1997; Nakhooda and Forstater, supra nt, 3; Streck, C, The Global Environment Facility- $A$ Role Model for International Governance,1(2), MIT Press Journals, 2001, 71, at <mitpressjournals.org/doi/abs/10.1162/152638001750336604> (accessed 18 November 2017).

6 The G8, which comprise of Britain, Canada, France, Germany, Italy, Japan, the United States and Russia, controls $68 \%$ of the world's monetized economy yet make up only $14 \%$ of the world's population. The G7 invited Russia to join in 1999, but in practice, Russia has limited leverage in this powerful group.

7 Cohen and Burgiel, supra nt, 5; Nakhooda and Forstater, supra nt 3); Clémençon, R, "What Future for the Global Environment Facility?" 15(1) The Journal of Environment and Development, (2006) 50, at $<$ journals.sagepub.com/doi/abs/10.1177/1070496506286438> (accessed 18 November 2017).

8 Global Environment Facility, REPORT: Annual Report 2015 - Financing Global Environment Benefits \& Climate Change Adaptation in Africa, 2015, at <afdb.org/file admin/uploads/afdb/ Documents/Publications/AfDB-GEF_ANNUAL_REPORT_2015.pdf> (accessed on 18 November 2017); Bayon, R, et al., Environmental Funds: Lessons Learned and Future Prospects, at $<69.90 .183 .227 /$ financial/trustfunds/g-fundlessons.pdf> (accessed 18 November 2017).

9 Australian Government, Australian Multilateral Assessment 2012 - Global Environment Facility, 2012, at <dfat.gov.au/about-us/publications/Documents/gef-assessment.pdf>; Global Environment Facility Evaluation Office, Fifth Overall Performance Study - Approach Paper - Sub-study on GEF Engagement with the Private Sector, June 18 2013, at <gefieo.org/sites/default/files/ieo/ieo-documents/ops5-ss-privatesector-engagement.pdf>

10 See Oxford Climate Policy, Muller, B, the Global Environment Facility (GEF) and the Reformed Financial Mechanism (RFM) of the UNFCCC, at <oxfordclimatepolicy.org/publications/documents/TheGEF andtheRFM.pdf> (accessed 18 November 2017). 
international waters, the ozone layer, land degradation and persistent organic pollutants. ${ }^{11}$ Since its inception the GEF has allocated $\$ 11.5$ billion, supplemented by more than $\$ 57$ billion in co-financing for over 3,200 projects in more than 165 countries. ${ }^{12}$ The GEF is currently the largest intergovernmental fund for environmental, climate change and development action. ${ }^{13}$

The three institutions carrying out the GEF's work, known as Implementing Agencies (IAs), are the World Bank, the United Nations Development Programme (UNDP) and the United Nations Environment Programme (UNEP). ${ }^{14}$ However, Executing Agencies were added in 1999, following criticism that the monopoly held by the three agencies contributed to widespread dissatisfaction with project performance. The GEF executing agencies include UN agencies (the Food and Agricultural Organization, the United Nations Industrial Development Organization and the International Fund for Agricultural Development) and development banks (Asian Development Bank, African Development Bank, Inter-American Development Bank and the European Bank for Reconstruction and Development). ${ }^{15}$

The GEF currently partners with 18 international agencies. ${ }^{16}$ Procedurally, the World Bank administers funding, ${ }^{17}$ UNDP oversees project development, and UNEP serves as the scientific and technical advisor. The remaining agencies contribute to the management and delivery of projects. ${ }^{18}$

11 Australian Government, Australian Multilateral Assessment 2012, Supra nt 9.

12 Congressional Research Service, Lattanzio, RK, International Environmental Financing: The Global Environmental Facility (GEF), June 3 2013, at <fas.org/sgp/crs/misc/R41165.pdf> (accessed on 18 November 2017).

13 Organization Strategy for Sweden's Cooperation with the Global Environmental Facility, supra nt, 2; The GEF consists of four trust funds: 1) the main GEF Trust Fund, which covers the expenses for the GEF's regular operations; 2) the Least Developed Countries Fund (LDCF) for climate adaptation projects in low-income countries; 3) the Special Climate Change Fund (SCCF) for supporting technology transfer etc.; and 4) the Nagoya Protocol Implementation Fund (NPIF), established by the Convention on Biological Diversity. The GEF also manages the Adaptation Fund under the Kyoto Protocol. The LDCF and SCCF together have their own Council, or governing board, which has the same composition as the GEF Council. See Nakhooda et al., The Global Climate Finance Architecture (ODI Working Paper 2013) 2, at <https://www. odi. org/ sites/odi.org.uk/files/odiassets/publications-opinion-files/9312.pdf $>$ accessed (22 November 2017).

14 The Global Environment Facility, Funding at <thegef.org/about/funding > (accessed on 18 November 2017); Nakhooda, and Forstater, supra nt 3.

15 Horta, supra nt 4; The Global Environment Facility, Fonseca, G, Global Environmental Facility: Operating with Multiple Implementing Agencies (FCPF Working Group on Multiple Delivery Partners), 10, September 5 2010, at <forestcarbonpartnership.org//sites/fcp/files/Documents/tagged/GEF-\%20operating\%20 with\%20multiple\%20IAs.pdf> (accessed 18 November 2017).

16 The World Bank, the United Nations Development Program (UNDP), the United Nations Environment Program (UNEP), the United Nations Food and Agriculture Organization, the United Nations Industrial Development Organization, the African Development Bank, the Asian Development Bank, the European Bank for Reconstruction and Development, the Inter-American Development Bank, the International Fund for Agricultural Development, the World Wildlife Fund, the Conservation International, the West African Development Bank (WADB), the Brazilian Biodiversity Fund, the Foreign Economic Cooperation Office, Ministry of Environmental Protection of China (FECO), the Development Bank of Southern Africa (DBSA), the Development Bank of Latin America and the International Union for Conservation of Nature.

17 See SSRN, Rossati, D, Inter-Institutional Dynamics of Global Climate Finance: Complementarity and Competition in the Emerging Practices of Coordination, 12, 2013, at <papers.ssrn.com/sol3/papers. cfm?abstract_id=2401309> (accessed 18 November 2017).

18 Lattanzio, supra nt 12; See United Nations Sustainable Development Knowledge Platform, Economic Commission for Europe (UNECE), Financing Global Climate Change Mitigation at <sus tainabledevelopment.un.org $/$ index.php?page $=$ view \&type $=400 \& n r=804 \& \mathrm{menu}=1515>($ accessed on 18 November 2017). 
The Implementing Agencies (IAs) are, thus, responsible for developing projects for GEF funding and implementing them through designated executing agencies in the specific country or region. The IAs also provide input on policies and programmes. They work closely with executing agencies through individuals called 'task managers', which are responsible for the day-to-day operations of individual projects. Executing agencies can be government bodies, other UN agencies, NGOs, universities, etc. The IAs are expected to administer projects within their areas of competence. For example, the World Bank specializes in investment projects, UNDP in technical assistance projects and UNEP in targeted research and enabling activities as well as international waters projects. In practice, there is some overlap among the IAs. ${ }^{19}$ Funding from the GEF is limited to countries, which qualify for technical assistance grants from UNDP or loans from the World Bank. ${ }^{20}$ Further, the country should meet the eligibility criteria established by the Conference of the Parties (COP) of the relevant convention. ${ }^{21}$ A recent comprehensive assessment by an independent panel of experts found that the GEF has been a 'catalyst for innovative programmes' and produced 'significant results' to improve the global environment. ${ }^{22}$

\section{Global Environment Facility Governance Structures}

The governance structure of the GEF comprises six sub-structures:

1. The GEF Council;

2. The Conference of the Parties (COPs) to the environmental conventions;

3. The GEF Assembly;

4. The GEF Secretariat (GEFSEC);

5. The Scientific \& Technical Advisory Panel (STAP);

6. The GEF Evaluation Office (GEF EO).

The GEF Council is the GEF's main decision-making body. It is responsible for 'developing, adopting and evaluating the operational policies and programs for GEFfinanced activities'. ${ }^{23}$ Thus, the Council must ensure that GEF policies, activities and programme are concordant with the purposes, scope and objectives of the facility. It must also develop and monitor the operational strategy of the GEF and review and approve the work programme of the GEF. This involves playing a central role in the project cycle of the GEF. The Council acts following the guidance of the Instrument for the Establishment of a Restructured GEF as well as the guidance of the Conference of the Parties (COPs) of the different conventions that it serves, whenever it acts as their financial mechanism. The relationship between the GEF and the COPs is set out in a Memorandum of Understanding (MOU), jointly prepared by the Executive Secretary of

19 Cohen and Burgiel, supra nt 5; Horta, supra nt 4.

20 Ibid.

21 The Global Environment Facility (GEF) Trust Fund, supra nt 14.

22 Global Environment Facility, GEF Dynamic Partnerships - Real Solutions (Introduction to GEF), February 1 2002, at <thegef.org/publications/gef-dynamic-partnerships-real-solutions-introduc ti on-gef $>$ (accessed 18 November 2017).

23 Broughton, E, The Global Environment Facility: Managing the Transition, June 2009, at $<$ ifri.org/sites/default/files/atoms/files/GEF_ManagingtheTransition.pdf> (accessed on 18 November 2017); Global Environment Facility, Instrument for the Establishment of the Restructured Global Environment Facility/12, March 2008, at <thegef.org/documents/instrument-establishment-restructured-gef> (accessed on 18 November 2017). 
the different conventions and the GEF CEO. ${ }^{24}$ The COPs assign functions and provide guidance to the GEF through common decisions.

The Council is composed of 32 constituency representatives, which represent the 178 countries, donor and recipient, that are parties to the GEF. Sixteen of these represent developing countries, fourteen represent developed countries and two represent economies-in-transition. The GEF CEO, or their representative, co-chairs Council meetings, along with a Council member elected for each Council meeting. Representatives of each of the Participant countries are invited to observe meetings, while representatives from the World Bank, UNDP, UNEP, the STAP and the conventions are invited to attend. ${ }^{25}$ The Council meets, at minimum, every six months. Decisions within the GEF Council are taken by consensus. If no consensus can be reached, decisions are taken through a formal vote by double-weighted majority, i.e., through an affirmative vote representing both a $60 \%$ majority of the total number of Participants and a $60 \%$ majority of the total financial contributions. ${ }^{26}$

The main role of the GEF Assembly is to review the activities of the GEF and to agree on amendments to be made to the Instrument. In this regard, the Assembly thus has the power to affect the operation of the GEF through a unanimous adoption of amendments to the GEF Instrument. More informally, the Assembly provides a crucial forum for debate on issues affecting the GEF since it is set to meet every three to four years, to coincide with the replenishment rounds of the GEF. The Assembly is composed of representatives of all the participant countries within the GEF, represented by Ministers and high-level governmental representations. Representatives from the World Bank, UNDP, UNEP, regional development banks and the different conventions as well as accredited major groups are invited to the Assembly meetings. ${ }^{27}$

GEFSEC ensures that the decisions taken by the Council and the Assembly are translated into effective action. This mandate involves overseeing the implementation of program activities and of operational policies by liaising with countries and with the Implementing Agencies in charge of the implementation of projects and reporting to the Council and the Assembly. It also involves a crucial coordination role- GEFSEC must facilitate coordination among and between the Implementing Agencies, the Conference of the Parties (COPs) of the conventions and the Secretariats of other relevant international bodies. While the World Bank supports it administratively, it remains functionally independent from it. The CEO of the GEF heads GEFSEC. ${ }^{28}$

The STAP is an advisory body to the GEF. It provides scientific and technical advice to the GEF on its strategy and programmes and provides evaluation on projects before they are approved. The STAP is composed of fifteen members who are scientific experts in one of the GEF's designated focal areas. The UNEP provides for its Secretariat. Finally, the GEF Evaluation Office (GEF EO) is the main body assessing the work of the GEF. It is nested within GEF offices, but operates independently from the GEF since 2003. It has a separate director and its offices and staff are located on a different floor than the GEF staff. The GEF EO produces an Overall Performance Study

24 Broughton, Ibid; Werksman, J, Consolidating Global Environmental Governance: New Lessons from the GEF?, 5, 2003, at <citeseerx.ist.psu.edu/viewdoc/download? doi=10.1.1.539.4746\&rep= rep1\& type=pdf> (accessed on 18 November 2017).

25 Broughton, Ibid; Global Environment Facility, Rules of Procedure for the GEF Council/11, May 2004, at $<$ https://www.thegef.org/publications/rules-procedure-gef-council> (accessed 18 November 2017).

26 Broughton Id, 21; Global Environment Facility, GEF, Rules of Procedure for the GEF Council Id, 16.

27 Broughton Ibid; Global Environment Facility, GEF, Rules of Procedure for the GEF Council Id, 7.

28 Ibid. 
(OPS) of the GEF every four years, in time for the replenishment round, as well as yearly Annual Performance Reports (APR) and ad hoc studies. ${ }^{29}$

\section{Global Environment Facility Funding Priorities and Guidelines}

The GEF finances the additional or incremental costs involved in converting a national scale project into a concern that has global environmental benefits. ${ }^{30}$ Incremental Costs is the difference in cost between a project with global environmental benefits and an alternative project without such global benefits. To be taken into consideration for GEF finance or GEF grants, a project proposal has to fulfil the following project selection criteria:

1. It is undertaken in an eligible country;

2. It is consistent with national priorities and programs;

3. It addresses one or more of the GEF Focal Areas, improving the global environment or advancing the prospect of reducing risks to it;

4. It is consistent with the GEF operational strategy;

5. It seeks GEF financing only for the agreed-on incremental costs on measures to achieve global environmental benefits; 4

6. It involves the public in project design and implementation; and

7. It is endorsed by the government of the country in which it will be implemented. ${ }^{31}$

The GEF raises and gathers money through a process of replenishment rounds. Every four years, coinciding with GEF Assembly meetings, donor countries pledge money to the GEF for a period of four years, until the next replenishment round. ${ }^{32}$ To access these funds, countries must submit project proposals and for every $\$ 1$ invested, GEF expects at least $\$ 3$ of co-financing, which varies based on the project themes and country of implementation. ${ }^{33}$ A History of GEF Replenishments is shown below:

Pilot Phase (1991-1994)

GEF-1 (1994-1998)

GEF-2 (1998-2002)

GEF-3 (2002-2006)

GEF-4 (2006-2010)

GEF-5 (2010-2014)

GEF-6 (2014-2018)
$\$ 1.00$ billion
$\$ 2.023$ billion
$\$ 2.075$ billion
$\$ 3.000$ billion
$\$ 3.135$ billion
$\$ 4.340$ billion
$\$ 4.43$ billion

There are four types of grants allocated through the GEF: 1. PDF (planning) Grants, 2. Full Project Grants, 3. Medium-Size Grants, and 4. Small Grants. The PDF Grants are used to support the short-term preparation of full project proposals for the inclusion in

29 Ibid.

30 See United Nations Digital Repository - Economic Commission for Latin America and the Caribbean, Acquatella, J, Carlos, DM, and Barcena Ibarra, A, Financing for Sustainable Development in Latin America and the Caribbean/ 10-11, October 12 2001, at <repositorio.cepal.org/handle/11362/22569> (accessed 18 November 2017).

31 The Global Environment Facility (GEF) Trust Fund, supra nt 14.

32 Broughton, supra nt 23, 28.

33 Mava Foundation, Gobin, C, and Landreau, B, Innovating Conservative Finance in West Africa and the Mediterranean, at <fr.mava-foundation.org/wp-content/uploads/2017/02/MAVA_Innovating ConservationFinance_VF-31Janv2017-v2-1.pdf $>$ (accessed 18 November 2017). 
GEF work programmes. Once a potential project has been identified it usually needs further preparation before a full project proposal can be developed. Funding to assist with project preparation is available through the GEF Project Preparation and Development Facility (PDF) which has three funding categories known as 'blocks'. Block A funds (up to $\$ 25,000$ ) are be available at very early stages of project identification. Block B (up to $\$ 350,000)$ are to be used for completing project proposals and preparing necessary supporting documentation. Finally, Block $C$ funds (up to $\$ 1$ million) are available for large scale projects to complete technical design and feasibility studies. Each block has its own documentation requirements and approval levels. ${ }^{34}$

Full Project Grants are for longer-term projects costing more than US \$1 million. They are mainly provided to governments following an incremental cost approach. However, NGOs and other nongovernmental entities are eligible for consideration as executing agencies, provided that the host government endorses the project. ${ }^{35}$ MediumSize Grants (MSG) are available for longer-term projects costing between $\$ 50,000$ and $\$ 1$ million. ${ }^{36}$ Governments, local community organizations, NGOs and academic institutions are eligible to apply. For MSPs to be eligible, they must (i) be based on the national priorities of the country in which they are to be conducted, (ii) coincide with the GEF's operational strategy and operational programmes, and (iii) be endorsed by the host country or countries. ${ }^{37}$

The Small Grants Programme (SGP) is created for projects costing up to $\$ 50,000$. The SGP is designed exclusively to support projects implemented by community-based organisations and NGOs for activities that address local problems related to the GEF focal areas. ${ }^{38}$ These programmes are managed by National Coordinators-either an NGO representative or an official based in the local UNDP office. National Coordinators are supported by National Selection Committees composed of other NGO representatives, as well as government and UNDP representatives. The latter two act as observers but participate when requested by the Committee's NGO members. These National Selection Committees review and approve Small Grant Project proposals for inclusion in the national GEF/SGP work programme.

The principal objectives of the SGP are to:

1. Demonstrate community-level strategies and technologies that can contribute to reducing threats to the global environment if they are replicated over time;

2. Draw lessons from community-level experience and support the spread of successful community-level strategies and innovations among community groups and NGOs, host governments, GEF, development aid agencies and others working on a larger scale;

3. Build partnerships and networks of local stakeholders to support and strengthen the capacities of community groups and NGOs to address environmental problems and promote sustainable development. ${ }^{39}$

\footnotetext{
34 Cohen and Burgiel, supra nt 5; Global Environment Facility, The Project Development and Preparation Facility (Council Meeting, February 22-241995, at <thegef.org/sites/default/files/council-meetingdocuments/GEF.C.3.JointSummary_5.pdf> (accessed on 19 November 2017).

35 Id, 13.

36 The April 1997 GEF Council Meeting approved a Medium-Size Projects Programme (MSP).

37 Cohen and Burgiel, supra nt 5, 34; GEF. July 1997. Global Environmental Facility: Medium-sized Project Kit.

38 Cohen and Burgiel, supra nt 5, 13, 38.

39 Ibid, 13.
} 


\section{Strengths of the Global Environment Facility System}

\section{A. A Financing Mechanism for Multilateral Environmental Conventions}

One of the core strengths of the GEF is its role as a financing mechanism for several multilateral environmental conventions that span most global environmental issues. ${ }^{40}$ The grouping of a number of different environmental treaties under the same financial mechanism has the potential to help address cross-cutting issues and avoid transferring negative environmental impacts between focal areas. Since, for example, deforestation impacts both climate change and biodiversity, the GEF could increase the effectiveness of all treaties by addressing them under one umbrella. Similarly, in the ozone focal area, the goal of reducing and eliminating the use of ozone depleting substances could contribute to reducing climate change since many ozone depleting gases are also potent greenhouse gases. ${ }^{41}$

The GEF serves as a financing mechanism for the Convention on Biological Diversity (CBD), the United Nations Framework Convention on Climate Change (UNFCCC), the Stockholm Convention on Persistent Organic Pollutants (POPs), and the United Nations Convention to Combat Desertification (UNCCD). It operates consistent with the guidance provided by the Conference of the Parties (COP) to the conventions. In October 2013, the international community adopted the Minamata Convention on Mercury, a global legally binding instrument, and agreed on the GEF's role as a financial mechanism for the new convention. The GEF also provides resources under the Montreal Protocol for economies-in-transition that are dealing with ozone depleting substances. Since its inception, the GEF has implemented its International Waters Program, which aims to improve the management of transboundary freshwater resources and large marine ecosystems. It has also provided funding to projects that generate multiple environmental benefits and that are consistent with the objectives of the United Nations Forum on Forests (UNFF). ${ }^{42}$

The GEF is versatile and adapts to changing challenges. A number of new programmatic areas have been added to the GEF over time. For example, sustainable forest management that benefits the agenda of the United Nations Forum on Forests was added in 2007. In 2010, with the assistance of several contributors, the GEF established the Nagoya Protocol Implementation Fund (NPIF) to specifically support the access and benefit-sharing objectives under the Convention on Biological Diversity. In parallel, as the case for considering adaptation and resilience grew stronger, at the request of the parties to the UNFCCC, two new funds were established under GEF purview, centred on funding climate change adaptation activities, the Least Developed Countries Fund and the Strategic Climate Change Fund ${ }^{43}$ The GEF has also played a key role in helping to harmonise work on the chemicals and waste conventions. ${ }^{44}$

40 Global Environment Facility, GEF 2020 Strategy-Global Environment Facility/11-12, at <thegef.org/sites/default/files/publications/GEF-2020Strategies-March2015_CRA_WEB_2.Pdf > (accessed May 25 2017).

41 The Global Environment Facility, Horta, supra nt 4.

42 Global Environment Facility, GEF 2020 Strategy-Global Environment Facility/11-12, supra nt 40.

43 Moreover since 2008, the GEF has also been providing secretariat services to the Adaptation Fund, which was established under the Kyoto Protocol.

44 Global Environment Facility, GEF 2020 Strategy-Global Environment Facility/11-12, supra nt 40. 


\section{B. The GEF Coordinates Bilateral and Multilateral Efforts and is an Embodiment of a Global Bargain}

The GEF has been a mechanism that catalyses coordination between bilateral and multilateral agencies when it comes to sharing knowledge of project pipelines in each country and focal area as well as at the strategic level of policy and programming. Although duplication of effort by the World Bank and UNDP was a serious problem at the beginning of the GEF's operational phase in 1994, joint pipeline reviews by all agencies reduced that problem. The GEF also offers a framework for broader consultation and cooperation among multilateral agencies on strategic approaches to programming in or across focal areas. For example, the GEF Focal Area Task Forces brings together GEF Secretariat specialists and representatives of the GEF agencies to discuss the strategic and effective allocation of GEF resources. This coordination mechanism does not eliminate the tendency toward competition among the GEF agencies but it does harness their common interest in using GEF funds to reduce threats to the global environment. ${ }^{45}$

Moreover, the GEF represents a hard-won bargain between donor and developing countries over priorities, programming strategies and specific project and program choices. Although neither group of states has been entirely happy with the result, one must nevertheless recognize that the GEF structure, as well as its operational principles, is the result of a continued balancing act between the interests of both sets of countries. GEF programming involves a reconciliation of the interests and views of the participants of the Rio Conventions, including both the host and recipient countries. ${ }^{46}$ The GEF Council offers the opportunity for donor country representatives to meet every six months to discuss policy and strategy for using their contributions to fund measures that address global environmental concerns. Indeed, Council meetings have provided opportunities for wider consultations among donors, recipient countries, multilateral agencies and the NGO community. ${ }^{47}$

\section{Transparency and Inclusiveness}

A chief strength is the GEF's strong, diverse and expanding network of implementing partners. Initially, the GEF was designed as a partnership between the United Nations Development Programme (UNDP), the United Nations Environment Programme (UNEP), and the World Bank Group (WBG) each acting as implementing partners in accordance with their comparative strengths. In the early 2000s, seven new agencies were added to the GEF partnership, thus, significantly broadening the GEF's technical expertise and implementation capacity and providing recipient countries with a broader array of choices when they implement GEF-funded projects. Since 2012, the GEF has undertaken a process to accredit additional project agencies. ${ }^{48}$

GEF programming is bolstered by a well-established institutional setup and an inclusive, equitable and transparent governance structure. When it was established in the early 1990s, their governance structure set a new standard, because the GEF Council has an equal number of seats for developing and developed countries. Progressively, many

45 World Wildlife Fund/Heinrich Boll Stiftung, Porter, G, et al., New Finance for Climate Change and the Environment, 15 July 2008, at <odi.org/sites/odi.org.uk/files/odi-assets/publications-opinionfiles/3882.pdf> (accessed on 19 November 2018); Global Environment Facility, Porter, G, et al., Study of GEF's Overall Performance, 1998, at <gefieo.org/sites/default/files/ieo /evaluations/ops1. pdf > (accessed on 19 November 2017).

46 Ibid.

47 Ibid.

48 Global Environment Facility, supra nt 40. 
GEF recipient countries are also becoming donors to the facility, thus, enhancing the overall ownership of the GEF's priorities and programmes. All project documents that face decision by the Council are at present being made available on the GEF website, along with other information. ${ }^{49}$ It maintains a comprehensive project database, where information on all projects that have been approved for funding (and those that have been cancelled) is accessible. The GEF operates with a relatively high degree of transparency, making most documentation on its operations and decisions publicly available, including through its website. ${ }^{50}$ Accountability is enhanced by the Independent Evaluation Office (IEO), which reports directly to the Council and provides ongoing monitoring and evaluation of project outcomes. In addition, GEF is advised by the standing Scientific and Technical Advisory Panel (STAP), which consists of world-class scientists and covers all GEF focal areas. The GEF applies best-practice fiduciary standards and has established high standards for environmental and social safeguards, gender mainstreaming, and engagement with civil society organizations and indigenous peoples. $^{51}$

The GEF has a record of delivering good results on the ground. Reports by the IEO repeatedly show that GEF projects deliver benefits. Most recently, the Overall Performance Study for GEF-5 (OPS-5) concluded that GEF projects are effective in producing outcomes: more than $80 \%$ of completed projects during GEF-5 received an outcome rating of at least moderately satisfactory, exceeding the international benchmark of $75 \%$. Consequently, OPS-5 concluded that the GEF is achieving its mandate and objectives and is relevant to the conventions and to regional and national priorities. Recent assessments conducted by key bilateral agencies also showed that the GEF delivers value for money invested. ${ }^{52}$

The GEF was the first financial institution to formally engage NGOs in its operations. NGOs are formally represented within the GEF through the GEF/NGO network, which is made up of 18 members, representing 15 regions and three representatives from Indigenous Peoples' Organizations, and coordinated by a focal point. At present, there are over 400 accredited NGOs. Observers can provide written inputs into the work programme of the fund. Furthermore, they select regional representatives who are invited to participate in Council meetings where they can make inputs at the invitation of the chair. Likewise, there is a one-day meeting with the GEF/NGO network alongside all meetings of the GEF council to create a platform for deliberation and debate. NGOs participate in the fund in a range of ways, including as project implementers. Indeed, some major international NGOs have recently been accredited as executing entities of the GEF. This has resulted in a diversity of interests and drivers for NGO participation in the GEF. ${ }^{53}$

Id, 13 .

50 Nakhooda, and Forstater, supra nt 3, 15.

51 Global Environment Facility, supra nt 40.

52 Ibid; UK Government/Department for International Development (DFID), Multilateral Aid Review, March 2011, at <gov.uk/government/publications/multilateral-aid-review> (accessed on 19 November 2017); Australian Government/ Department of Foreign Affairs and Trade, Australian Multilateral Aid Assessment, March 2012, at <dfat.gov.au/about-us/publications/Pages/ australian -multilateralassessment-ama-full-report.aspx> (accessed 19 November 2017).

53 Nakhooda, and Forstater, supra nt 3. 


\section{Challenges of the Global Environment Facility System}

\section{A. Rises in Global Environmental Issues and Low Level of Funding by Donor Countries}

The past decade has seen a rise in the significance of global environmental issues on the political agendas of many countries. Proposed policies have not only attempted to address the environmental implications of greenhouse gas mitigation and climate change adaptation but have also become linked to energy and infrastructure issues through international economic, trade and geopolitical concerns. To address these issues, governments have begun to incorporate many global environmental objectives into their sustainable growth and development strategies. Funding for these activities has increased, and various institutional responses for this extensive portfolio are under consideration. $^{54}$

Thus, the amounts needed to address global environmental issues are extremely high. In the climate change sector, where a number of reports on the costs of addressing climate change have been produced, bringing back global $\mathrm{CO} 2$ emissions to current levels by 2050 requires an estimated $\$ 17$ trillion in additional investment in the energy sector between now and 2050. Therefore, any impression that the GEF would be able to solve global environmental problems on its own needs to be qualified immediately. ${ }^{55}$ Indeed, GEF was created as a 'catalyst' for taking measures to confront global environmental challenges and is not aimed specifically at countering global threats. This serves to show that the logic underlying GEF, namely how a minimal incremental grant financing may result in 'multi-state investment for transformational change', could indeed be faulty. ${ }^{56}$

More so, GEF has a difficult standing among some of its 177 members. Resistance to its work originates from both camps. ${ }^{57}$ Whereas some of its sponsors have repeatedly failed to meet their funding obligations, some of the recipients resist the increasing scope of the Facility's activities and are unwilling to distribute funds among too many focal areas. ${ }^{58}$ In light of this opposition, some critics have voiced doubts about the Facility's innovative impulses. Consequently, it has been posited that the GEF has to make considerable co-coordinative efforts in order to preserve a reasonably peaceful working relationship between implementing agencies and associated organizations; a role, which does not grant much leeway for supporting experimental or cutting-edge projects. ${ }^{59}$

\section{B. The Changing Role of Multilateral Development Banks in Environmental Funding} Multilateral Development Banks (MDBs) are key actors in the global system of environmental financing. Some have argued that, as commercial lending institutions, they dispense funds more efficiently than many institutional programmes, such as the GEF. However, as primary mechanisms for economic development, their past

54 Lattanzio, supra nt $12,10$.

55 Broughton, supra nt 23; International Energy Agency (IEA), Energy Technologies Perspective, 2008, at $<$ iea.org/Textbase/npsum/ETP2008SUM.pdf> (accessed on 19 November 2017); Global Environment Facility Evaluation Office, Fourth Overall Performance Study, 17 July 2008, at <issuu.com/gefieo/docs/2010_ops4_progress_toward_impact> (accessed 19 November 2017).

56 Lattanzio, supra nt 12, 10-11.

57 Donor/developed countries and recipient/developing countries.

58 Stephan, HR, and Zelli, F, The Role of International Organizations in Global Environmental Governance (Routledge 2009); DeSombre, ER, Global Environmental Institutions (Routledge 2006).

59 Stephan, and Zelli, Ibid; Young, Z, A New Green Order? The World Bank and the Politics of the Global Environment Facility (Pluto Press 2002). 
environmental lending practices have demonstrated perceived conflicts of interest. ${ }^{60}$ Objectives began to shift in 2005 when MDBs were encouraged by G-8 leaders to play a more leading role in sustainable development and environmentally friendly technologies. ${ }^{61}$ Since this time, MDBs have launched many new initiatives to address the environment, including efforts to:

(1) Account for GHG emissions and improve energy efficiency;

(2) Support renewable energy;

(3) Manage forests sustainably;

(4) Promote carbon finance; and

(5) Adapt to climate change.

GEF programmes now find themselves in competition with many of the new initiatives in MDBs' portfolios. ${ }^{62}$

\section{Increases in New Bilateral, Multilateral, and Private Funding Mechanisms Resulting from Slowness of GEF Project Initiation and Implementation}

Despite the significant financial flows that are channelled through the GEF, one of the main criticisms is the complex and cumbersome project cycle which involves several stages of review and approval by the implementing agencies and other GEF bodies and can take up to 22 months for approval. ${ }^{63}$ For example, GEF's two-layer structure means that all funding must be approved twice, by GEF itself and the relevant GEF Agency, leading to inefficiencies. ${ }^{64}$ The length of the activity cycle can be attributed to the number of actors involved in it. Applicants have to go through the procedures of both the GEF and the agencies that have been chosen as their Implementing Agencies (IAs), while their projects must also follow COP directives. This leads to certain administrative tasks, such as the preparation of evaluation papers and all report papers, to have to be done twice. This set-up also means that the activity cycle may be disrupted by incongruent procedures between the GEF and the IAs. Poor connections between the time-bound GEF decision points and the Agency cycles are a major cause of delays. The complexity

60 The development portfolios of most MDBs strongly emphasize a bias toward conventional fossil fuel power generation and infrastructure loans that often worked counter to environmental aims (e.g.: The World Bank loaned more than $\$ 2.5$ billion for conventional power projects in 2005 compared to $\$ 109$ million for renewable energy or energy efficiency). See Porter et al., supra nt 45.

61 See International Finance Cooperation/ World Bank Group, Catalyzing Private Investment for a Low Carbon Economy: World Bank Group Progress on Renewable Energy and Energy Efficiency in Fiscal 2007, 2007, at <ifc.org/wps/wcm/connect/topics_ext_content/ifc_external_corporate_site_sustain ability-atifc/publications/publications_report_catalyzingprivateinvestment_wci_1319578638 519> (accessed at 19 November 2017); See the Gleneagles Plan of Action at the 2005 G-8 Meeting in Gleneagles, Scotland. It should be noted that the portfolios of many MDBs still retain significant provisions for conventional power and infrastructure projects as compared to most bilateral environmental aid, albeit with a greater ratio of renewable and efficiency resources than in the past. See Hicks, RL, et al., Aid: Understanding the Environmental Impact of Development Assistance (Oxford University Press 2008).

62 Lattanzio, supra nt 12.

63 Friedrich Ebert Stiftung/ International Policy Analysis, Johl, A and Lador, Y, A Human Rights-based Approach to Climate Financel 8, 2012, at <ciel.org/Publications/ClimateFinance_Feb2012. pdf> (accessed on 19 November 2017); World Resources Institute, Ballesteros, A, et al., Power, Responsibility and Accountability: Re-thinking the Legitimacy of Institutions for Climate Financel 32, 2010, at <wri.org/sites/default/files/pdf/power_responsibility_accountability_executive_summ ary.pdf> (accessed on 19 November 2017); See GEF (Global Environment Facility), GEF Project Cycle (GEF/C.31/7 and GEF/C.31/7/Corr1, June). Washington, D.C.: GEF. 2007)

64 Lattanzio, supra nt 12, 10-12. 
of procedures also slows down the project cycle. Indeed, actors dealing with the GEF have trouble knowing what actions they are supposed to take, at what point in the activity cycle, and how such actions should be formulated. This problem has been compounded by the fact that guidelines for procedures within the GEF change frequently. ${ }^{65}$ More so, GEF's lack of legal status (the trust is held by the World Bank) prevents it from disbursing funding directly to countries with a one-step approval process. ${ }^{66}$

As a result, many donor governments believe that the existing environmental finance system has not produced satisfactory results. In searching for new and effective approaches to environmental funding, donors have sought options that can be organized quickly, administered directly and be demonstrated to produce a more significant impact on the environment. Many have turned to highly specified multilateral programmes, bilateral or even private sector measures to accomplish these aims and no fewer than 15 environmental finance mechanisms have been announced since $2007 .{ }^{67}$

Additionally, developed countries seem to be looking for alternatives to the GEF in their actions towards the management of global environmental issues. ${ }^{68}$ In particular, they were at the root of the World Bank's Climate Investment Funds (CIFs), ${ }^{69}$ which was launched at the Gleneagles G8 summit under the impulsion of the United Kingdom and whose activities 'overlap substantially' with those of the GEF. ${ }^{70}$ It was stated that the financial commitment signalled by the UK was conditional to the new funds being nested specifically within the World Bank, rather than the GEF. ${ }^{71}$ Also, when the decision was taken to create the Adaptation Fund $(\mathrm{AF})^{72}$ within the United Nations Framework

65 Broughton, supra nt 23, 67; Global Environment Facility Evaluation Office, Joint Evaluation of the GEF Activity Cycle and Modalities, 2007, at <gefieo.org/sites/default/files/ieo/evaluations/gef-activity-cyclemodalities.pdf $>$ (accessed on 19 November 2017); Global Environment Facility/Office of Monitoring and Evaluation of the Global Environment Facility, OPS3: Progressing Towards Environmental Results Third Overall Performance Study of the Global Environment Facility/55, 2005, at <gefieo.org/sites/default/files/ieo/evaluations/ops3-executive-version.pdf> (accessed 19 November 2017).

66 Lattanzio, supra nt 12.

$67 I d, 11$.

68 For example, while the GEF may play a significant role in the future, there is widespread skepticism, particularly in some developed countries, about using it to channel vastly scaled-up climate funds as part of a future international regime. See Council on Foreign Relations, / International Institutions and Global Governance Program, Michonski, K, and Levi, MA, Harnessing International Institutions to Address Climate Change, March 2010, at <iadb.org/intal/catalogo/PE/2010/05037.pdf> (accessed 19 November 2017) 7.

69 The CIFs comprise the Clean Technology Fund and the Strategic Climate Fund. The Climate Investment Funds were set up within the World Bank as interim financial mechanisms to serve until an agreement on the post-Kyoto governance architecture for climate change has been signed. They are to provide additional grants and concessional funding to developing countries, to address urgent climate change challenges. See World Bank, Climate Investment Funds, at http://web.worldbank.org/WBSITE/EXTERNAL/TOPICS/ENVIRONMENT/EXTCC/0,,content MDK:21713769 menuPK:4860081 pagePK:210058 piPK:210062 theSitePK:407864,00. $\mathrm{html}$ (accessed 29 November 2017) 7.

70 Porter et al., supra nt 45, 9.

71 Broughton, supra nt 23, 56.

72 The Adaptation Fund (AF) was established in 2001 under the Kyoto Protocol to finance adaptation projects in developing countries that are parties to it. The fund is to be financed with a $2 \%$ share of the proceeds from activities within the clean development mechanism (CDM). It will also receive funds from other sources. (The CDM allows countries with emission reductions under the Kyoto Protocol to implement emission-reduction projects in developing countries, and gain emissions credit from it.) The GEF provides secretariat services to the AF, while the World Bank serves as its trustee. It is managed by the Adaptation Fund Board (AFB), under the authority and guidance of the UNFCCC. See 
Convention on Climate Change (UNFCCC), developing countries lobbied, through the G77+China, to prevent the GEF from becoming its operating entity. The most frequent justifications invoked were the difficulty in accessing GEF funds, the complexity of its governance structure compared to the establishment of direct access of eligible Parties to Adaptation Funds (AFs), and the desire to 'give developing countries a more direct and equitable voice in how funds are prioritized and spent' by exempting the fund from the decision-making procedures of the GEF. ${ }^{73} \mathrm{GEF}$ is in competition with many of these budding initiatives for a share of environmental funding. ${ }^{74}$

\section{Difficulties in Defining and Calculating 'Incremental' and 'Additional' Costs}

As stipulated in the GEF Instrument, grants cover the 'incremental' ${ }^{75}$ or 'additional' cost of 'transforming a project with national benefits into one with global environmental benefits'. GEF finances the incremental and additional costs involved in converting a national scale project into a concern that has global environmental benefits. ${ }^{76}$ Incremental cost calculations have also been used as preference in project selection. While the concept of incremental cost is an essential element for GEF funding, no proper guidance is provided to Multilateral Environmental Agreements (MEAs) or other interested stakeholders on how to effectively develop proposals on that basis. ${ }^{77}$ Historically, GEF's implementing agencies have had difficulty producing a coherent methodology for calculating incremental cost, slowing the rate of project development. ${ }^{78}$

Every project proposal presented to the GEF had to provide a calculation of its estimated incremental costs. Such a concept was problematic from the onset. While useful in political terms, it did not make much sense in practical ones. It has been noted that the concept of incremental costs is fundamentally an international cooperation tool and, as such, should not be used as scientific guidance. ${ }^{79}$ As early as the Pilot Phase, Mohammed El-Ashry, then GEF CEO, stated that 'there are many instances where it is difficult to distinguish global and national environmental benefits', just as there are many

Government of the Republic of South Africa/ Department of Environmental Affairs, United Nations Framework Convention on Climate Change (UNFCCC) Adaptation Fund, 2017, at <environment.gov.za/projectsprogrammes/donorfunded/unfccc\#adap tationfund> (accessed 12 August 2017).

73 Broughton, supra nt 23, 55; Oxford Institute for Energy Studies, Müller, B, and Winkler, H, One Step Forward, Two Steps Back? The Governance of the World Bank Climate Investment Funds /3, February 2008, at <oxfordenergy.org/wpcms/wp-content/uploads/2011/01/Feb-2008 Govern anceoftheWorldBankClimateInvestmentFunds-BenitoM\%C3\%BCllerandHaraldWinkler.pdf>

(accessed on 19 November 2017); Engineering News, Spadavecchia, OS, New \$500m fund to help developing countries adapt to climate change, 11 December 2007, at http://www. engineeringnews. co.za/article/new-500m-fund-to-help-developing-countries-adapt-to-climate-change-2007-12-11 (accessed 19 November 2017).

74 Lattanzio, supra nt $12,11$.

75 It is noteworthy that this guideline has been criticized as failing to address 'the underlying political causes of environmental degradation in developing countries'. See DeSombre, supra nt 58, 160; See also, Abbott, KW, and Gartner, D, The Green Climate Fund and the Future of Environmental Governance (Earth System Governance Working Paper No. 16. Earth System Governance Project 2011), 5, at <https://papers.ssrn .com/ sol3/papers.cfm?abstract_id=1931066> (accessed 22 November 2017).

76 See Congressional Research Service, Lattanzio, supra nt 12, 12.

77 Inomata, T, and Cazeau, JW, Post-Rio+20 Review of Environmental Governance within the United Nations System (United Nations, Geneva 2014) 51, at <https://www.unjiu.org/en/ reportsnotes/JIU\%20Products/JIU_REP_2014_4_English.pdf> (accessed 22 November 2017).

78 Lattanzio, supra nt 12.

79 Broughton, supra nt 23; Labbate, G, "The Incremental Cost Principle and the Conservation of Globally Important Habitats: A Critical Examination” 65 Ecological Economics (2008) 216-224. 
instances where it is difficult to separate global and national causes of environmental degradation and to determine a global or a national level of action ${ }^{80}$ In a 1998 study, recipient governments 'lodged strong complaints about Incremental Costs, either in terms of its lack of clarity or the process by which it is decided'. Respondents stated that the incremental costs concept was 'meaningless', that it leads to arbitrary and manipulative changes in project activities and that it was so frustrating that people 'do not want to apply to GEF'. Others complained the incremental costs calculations were 'unilaterally determined' by Implementing Agencies. ${ }^{81}$

For example, would recipient nations have cleaned up dumpsites leaching pollutants on their own as part of a national waste management or clean water strategy? Or is the chemical mess dumped by transnational corporations a global problem and the responsibility of donors? The dichotomization of benefits inherent in the incremental costs calculation has continued to fuel tensions between Implementing Agencies and governments to this day. Evaluators have recommended a 'negotiating framework to reach agreement' on the definition and use of the incremental cost concept. ${ }^{82}$

The incremental cost tool, by its nature, is biased towards technological, marketbased solutions. It is much easier to quantify benefits from technology transfer projects than from approaches that cannot easily be priced or measured. Projects that emphasize low cost technology or indigenous knowledge, local stewardship or public education all create global environmental benefits (and domestic ones too), but don't fit nicely in the incremental cost formula. Under the new Persistent Organic Pollutants (POPs) focal area, for example, cost effective options, including integrated pest management, are not technically eligible for funding. These techniques, which avoid chemicals, are often lowtech and familiar. The cost of adopting them can be less than the continued use of toxic pesticides. As a result, their incremental costs are negative and technically cannot be funded by the GEF. ${ }^{83}$

Further, technologies are usually directed at proximate rather than root causes of environmental destruction. The GEF funds the conversion from one powerful ozone depleting-substance to a less potent one, but it will not fund a final conversion to ozonesafe alternatives. Nowhere does the GEF address the issues of consumption that fuel the need for these environmental harmful substances. Sustainability to the GEF is viewed as financial sustainability - will the projects survive; will the initiative make money? The assumption that one conserves biodiversity not for the inherent values of species and habitat protection, but to make money from it has caused no end to difficulties for the GEF and done little good for conservation. ${ }^{84}$

\section{E. Unsuccessful History of Leveraging the Private Sector}

For compelling reasons, the private sector is of a high priority in addressing global environmental challenges. The private sector dominates the socioeconomic sphere and, therefore, limited public sector resources need to be used most effectively to redirect private sector activities toward environmentally sustainable approaches. Private

$80 \quad I d, 69$.

81 Horta, supra nt 4; The World Bank, Porter, Clemencon, R, Ofosu-Amaah, W and Phillips, M, Study of GEF's Overall Performance/70-71, 1 January 1998, at <documents.worldbank.org/curated /en/400381468179941343/Study-of-GEFs-overall-performance> (accessed 19 November 207).

82 Id, 13; Global Environment Facility. Second Overall Performance Study of GEF/60. October 2002, at $<$ www.thegef.org/council-meeting-documents/second-overall-performance-study-gef-0> (accessed 19 November 2017).

83 Ibid.

84 Id, 14. 
enterprises, which are the dominant source of economic activity, must be encouraged to pursue commercially viable activities that also generate global environmental benefits. An advantage of the GEF compared with other institutions lies in its ability to provide grant funding that can be targeted to provide much-needed enabling policy support that can reduce investment risks, thereby helping to alleviate systemic barriers to private investment. ${ }^{85}$

However, while GEF has long recognized a need to mobilize investment resources in the private sector, successful collaboration may require a degree of experience and commitment that GEF cannot achieve under its existing structure. The length and uncertainty inherent in the GEF project cycle may make participation less attractive to the private sector, and the organisation's emphasis on government entities at the expense of forming relationships with investors and manufacturers may serve as a further impediment. ${ }^{86}$ The Fifth Overall Performance Study of the GEF noted that the GEF's ability to engage the private sector has diminished as a result of the resource allocation system. ${ }^{87}$

\section{Positioning the Global Environment Facility for Greater Effectiveness: The Need to Address the Drivers of Environmental Degradation}

The GEF is mandated to finance incremental costs, i.e. new and additional funding that would not have been provided by other sources. This guideline has been criticised as failing to address 'the underlying causes and drivers of environmental degradation'. ${ }^{88}$ The 2020 vision for the GEF is set to be a champion of the global environment, building on its role as a financial mechanism of several multilateral environmental conventions (MEAs), supporting transformational change, and achieving global environmental benefits on a larger scale. To achieve this vision, the GEF needs to address the drivers of environmental degradation by proactively seeking interventions that focus on the underlying driving forces of global environmental degradation and support coalitions that bring together partnerships of committed stakeholders around solutions to complex environmental challenges. ${ }^{89}$

It has been posited that the GEF can enhance environmental benefits by addressing the drivers of environmental degradation. Environmental degradation drivers arise from the supply and demand of goods and services, which in turn generate environmental pressures that directly affect the state of the environment. To illustrate, efforts to prevent biodiversity loss can happen at multiple points in the causal chain. For instance, rising demand for beef may result in added pressure to clear land for pastures, leading to further deforestation, soil degradation, and biodiversity loss. Focusing more on upstream drivers in this same problem would enable the GEF to deliver cascading global environmental benefits down the causal chain, thereby progressively reducing the impacts of the original driver and increasing the overall benefits of interventions. By addressing environmental degradation at a systemic level, the need for subsequent remedial action - which is often much more expensive, if not impossible - would also be reduced. ${ }^{90}$

\footnotetext{
85 Global Environment Facility, supra nt 40, 30.

86 Lattanzio, supra nt 12.

87 OPS5 Fifth Overall Performance Study of the GEF, supra nt 9, 6.

88 Stephan and Zelli, supra nt 58, 8; DeSombre, supra nt 58, 160.

89 Global Environment Facility, supra nt 40, 15.

90 Id, 17-18.
} 
One of the most serious criticisms of the GEF's Biodiversity portfolio raised by a 2002 study was that the projects fail to address the underlying causes of biodiversity loss. Conserving an area of biodiversity will have limited long-term impact if economic, political and social issues threatening species and habitats are not addressed concurrently. While the GEF was never designed to address underlying issues, such as the need for land reform, unsustainable pressure on natural resources and global and local market pressures to destroy wildlife, its projects fail in part because these issues are not being addressed elsewhere. The GEF's Governing Council does not challenge the often antienvironmental priorities of its donor governments or the World Bank, the International Monetary Fund (IMF) and the World Trade Organization (WTO). The WTO fosters an export-led development model that puts immense pressure on natural resources in Global South countries. For example, the Structural Adjustment Programmes (SAPs) that was imposed upon the South as conditions for both new loans and debt relief by institutions, including the World Bank and International Monetary Fund call for increased exports to generate foreign exchange to service debt. ${ }^{91}$

Southern countries' greatest exports tend to be raw natural resources including timber, oil and natural gas, minerals, cash crops and fisheries. SAP pressures result in the acceleration of resource extraction and commodity production that are not ecologically sustainable. Deforestation, land degradation and desertification, soil erosion and salinization, biodiversity loss, increased production of greenhouse gases, increase in water-borne disease, the flooding of productive land and air and water pollution are but a few of the long-term environmental impacts that can be traced to the imposition of Structural Adjustment Programmes. In addition, SAPs-induced government cutbacks mean less money for the development and enforcement of environmental regulations, as well as the removal of food and agricultural subsidies that protect the poor. Additionally, a large proportion of GEF spending flows back to the Global North through procurement contracts. $^{92}$ In 1997, for example, the value of GEF procurement contracts sourced from all recipient countries was equivalent to what was sourced from the US and UK alone. ${ }^{93}$

Addressing drivers of environmental degradation will help the environmental conventions to better achieve their goals with support from the GEF as their financial mechanism. Conventions and recipient countries recognize that a focus on underlying drivers is critical for their long-term success. For example, the Strategic Plan for Biodiversity 2011-2020 and the Aichi Biodiversity Targets (collectively, the Aichi Targets), in reflecting on the status of the previous 2010 targets, both emphasize that 'there has been insufficient integration of biodiversity issues into broader policies,

91 Horta, supra nt 4, 12; McCormick, J, Comparative Politics in Transition ( $7^{\text {th }}$ ed, Cengage Learning 2010), 426; See News Rescue, How the IMF-World Bank and Structural Adjustment Programme (SAP) Destroyed Africa, May 26, 2009, at <newsrescue.com/how-the-imf-world-bank-and-structural-adjustmentprogramsap-destroyed-africa/\#axzz4ysHkZZp0> (accessed 10 August 2017); News Rescue, IMF Forces African Nations to Remove Fuel Subsidies, January 1, 2012, at <newsrescue.com/imf-forces-africannations-to-remove-fuel-subsidies/\#axzz4ysHkZZp0> (accessed 19 November 2017); Centre for Economic and Policy Research, Naiman, R, and Watkins, N, A Survey of the Impacts of IMF Structural Adjustments in Africa: Growth, Social Spending, and Debt Relief/1-5, April 1999, at <cepr.net/documents/publications/debt_1999_04.htm> (accessed 19 November 2017); Pambazuka News, Dembele, DM, The International Monetary Fund and World Bank in Africa: A 'disastrous' record, September 23 2004, at <pambazuka.org/governance/international-monetary-fund-and-world-bankafrica-disastrous-record $>$ (accessed 19 November 2017).

92 Horta supra nt 4, 13

93 Ibid; Global Environment Facility, Summary Report of the Co-Chairs Planning Meeting for the Second GEF Replenishment, March 12 1997, at <thegef.org/sites/default/files/council-meetingdocuments/C.9.Inf_.6_5.pdf> (accessed 19 November 2017); McCormick, supra nt 91; News Rescue, supra nt 91; Naiman and Watkins, supra nt 91. 
strategies, programmes and actions, and therefore the underlying drivers of biodiversity loss have not been significantly reduced'. The strategic plan also noted that among the multiple entry points that need to be pursued to achieve a positive outcome by 2020 is 'action to address the underlying causes of biodiversity loss, including production and consumption patterns, by ensuring that biodiversity concerns are mainstreamed throughout government and society'. ${ }^{94}$

Similarly, reducing Green House Gas (GHG) emissions, for instance, sufficiently to achieve 'stabilization of greenhouse gas concentrations in the atmosphere at a level that would prevent dangerous anthropogenic interference with the climate system' will not be possible without influencing the underlying drivers that stem from the growing demand for energy and without reducing fossil fuel-based energy production in favour of renewable energy. Similarly, in the chemicals and waste area, to ultimately reduce the production and use of harmful chemicals would require a focus on supply chain management and production techniques. ${ }^{95}$

Altering demand toward more sustainably produced goods and services is an important avenue to reducing environmental degradation. Although the GEF has a range of tools at its disposal in this regard, more needs to be done. These tools include certification standards for consumer goods, such as those the GEF supports through the Rainforest Alliance and private sector partners. ${ }^{96}$ They also include the introduction of a system of payment for ecosystem services (PES), which corrects distortions that would otherwise lead to unsustainable resource use and depletion of natural capital and incentives that reinforce the value of ecosystem goods and services. The GEF has been a pioneer and has committed significant seed funding to these schemes in several countries. Moreover, innovative financing models, such as partial risk guarantees, can help stimulate demand for more energy-efficient equipment in both households and industries and can facilitate more sustainable production and consumption of goods and services. ${ }^{97}$

Additionally, a key priority for the GEF will be to help change the production of goods and services in a manner that reduces or eliminates adverse impacts on the environment. Although the GEF has made some positive input in this respect, more work remains to be done. GEF's input in this area is comprised of: promoting a range of experiences in the supply of environmentally sustainable goods and services, including introducing standards for electricity consumption in households and industry appliances (as in the GEF's en.Lighten Project), improving agricultural practices to preserve soil health and, thereby, enabling food security (as in the GEF-supported project in Senegal's Groundnut basin), eliminating the use of persistent organic pollutants in economic processes (such as the use of DDT in the production of the pesticide Dicofol in China), and helping to reduce the threat of invasive species in marine ecosystems through strengthened regulation of shipping ballast water. The GEF also aims to continue

94 Global Environment Facility supra nt 40, 19; Convention on Biological Diversity, Strategic Plan for Biodiversity 2011-2020, at< cbd.int/sp/default.shtml> (accessed on 19 November 2017); Convention on Biological Diversity, Aichi Biodiversity Targets, at <cbd.int/sp/targets/default.shtml> (accessed on 19 November 2017). This priority is also reflected in the Aichi Target's Strategic Goal A, 'Address the underlying causes of biodiversity loss by mainstreaming biodiversity across government and society.' A number of targets under Strategic Goal B "Reduce the direct pressures on biodiversity and promote sustainable use") support focusing on sustainable production in agricultural production (including fisheries).

95 GEF 2020-Global Environment Facility, supra nt 40, 19; Article 2, UN Framework Convention on Climate Change (1992) A/RES/48/189.

96 GEF 2020-Global Environment Facility supra nt 40, 19.

97 Ibid. 
exploring options for working across entire supply chains and focusing on industry-wide approaches. ${ }^{98}$

Critically, addressing drivers of environmental degradation has the potential to deliver integrated solutions. Many global environmental challenges are interlinked and share common drivers. Biodiversity loss, climate change, ecosystem degradation, and pollution often share common drivers and may demand coordinated responses. For example, unsustainable agricultural production contributes approximately one-quarter of global Greenhouse Gas (GHG) emissions. Likewise, it is a leading cause of hypoxia in aquatic systems and it can cause deforestation and habitat destruction, thus, prompting further loss of biodiversity. By targeting key drivers, the GEF can magnify the effects of its investments, making them add up to more than the mere sum of their parts. Interdependence between environmental challenges is an additional reason for considering integrated approaches. For example, ecosystem degradation may happen faster as a result of vulnerabilities created by climate change. Research suggests that combined effects markedly increase the probability that critical thresholds of irreversible change will be crossed faster than predicted for each factor separately. ${ }^{99}$

\section{Conclusion and Future Outlook}

The Global Environment Facility (GEF) is today an important factor in the field of environmental governance. It remains the operating entity for the financial mechanisms of a number of Multilateral Environmental Agreements (MEAs), establishes a crucial source of money and technical assistance projects to countries with scarce capacities, and it provides an important learning and meeting ground for all actors involved in the financing of global environmental protection. However, these responsibilities are being overshadowed by the efficiency and financial challenges faced by the GEF, as well as by the blurring of the facility's comparative advantage over other donors. The latter phenomenon is aggravated by the proliferation of initiatives in the international environmental governance field, ${ }^{100}$ particularly in relation to international environmental financing.

The main challenge seemingly affecting the GEF today and which appears to take over from the efficiency issue since it emerged in the past couple of years is relating to the definition of the GEF's role in the changing international environmental governance (IEG) architecture. Solving the efficiency issue is part of the answer to this challenge, for the GEF can only be useful if it is efficient enough. In order to be effective and attractive to users, ${ }^{101}$ the GEF cannot continue to operate in the same way as it did in the past. It must be more adaptable, flexible and innovative, and that means shedding the legal and institutional rigidities that have constrained it. This, however, is not the complete answer; the question of the GEF's role in today's international environmental governance (IEG) needs to be tackled. ${ }^{102}$

Consequently, GEF's vision for 2020 seeks to address the efficiency challenge and clarify GEF's role in the international environmental governance arena particularly, as it relates to international environmental financing. It states that the 'vision for 2020 is to be a champion of the global environment by creating partnerships and strategically investing in solutions that:

$98 I d, 19-21$.

99 Ibid, 22; Scheffer, M et al., "Early-Warning Signals for Critical Transitions" 461 Nature International Journal of Science (2009), 53-59, at <nature.com/articles/nature08227> (accessed 19 November 2017).

100 Ibid, 95.

101 Ibid.

102 Ibid, 75. 


\begin{abstract}
A) Address the underlying drivers of global environmental degradation. With an emphasis on driver-focused solutions, we will be able to address the root causes of environmental degradation at local, national and international levels, while still addressing important environmental pressures where critical for the delivery of global environmental benefits. We will give preference to proactive over reactive approaches, with a view to enhancing our impact.

B) Innovate and achieve global environmental benefits at scale. Our funds should be invested in projects that are highly innovative and have the potential to be scalable across multiple countries and regions, rather than a one-off project in a country. These projects should also aim to stimulate policy, market or behavioural transformations. While working at the individual country level, we will focus on how countries actions can be scaled up to create spill over that have larger regional and global environmental benefits.

C) Deliver the highest impact, cost-effectively. We must focus on maximizing the global environmental benefits we can create with our funds by identifying costeffective solutions to global environmental challenges. ${ }^{103}$
\end{abstract}

Although the 2020 vision of the GEF is laudable for having the potential of repositioning the GEF at the forefront of international environmental financing, it can only be achieved with support from governments at all levels and stakeholders in the field of international environmental governance particularly. This is because it relates to international environmental financing. This paper, therefore, defends the view that political support from governments at all levels, improved financial support from donor countries and organisational and institutional support from other environmental-based institutions and non-governmental organisations should be given to the GEF to enable it to fulfil its mandate of global environmental protection through environmental protection financing. These recommendations, if adopted, will surely strengthen and reposition the GEF as a central player in the field of international environmental financing and help to address the numerous pressing global environmental challenges more effectively.

$*$

\author{
www.grojil.org
}

103 Global Environment Facility, GEF 2020 Strategy Paper for the Global Environment Facility (DRAFT), 4 September 2013, at <thegef.org/documents/gef-2020-strategy-paper-global-environment-facility-draft$0>$ (accessed 19 November 2017). 